\title{
Implementation of the Balanced Scorecard: The Case of Star-Class Hotels in Sri Lanka
}

\author{
Dileepa N. Samudrage \\ Department of Accounting \\ University of Sri Jayewardenepura, Sri Lanka \\ dileepask@sjp.ac.lk \\ DOI: 10.31364/SCIRJ/v7.i9.2019.P0919696 \\ http://dx.doi.org/10.31364/SCIRJ/v7.i9.2019.P0919696
}

\begin{abstract}
Although there are numerous studies carried out to study the Balanced Scorecard (BSC) as a performance measurement system, there is a dearth of research studies on the post-implementation issues of BSC, especially in hotel industry in Sri Lanka. Therefore, this study attempts to address the research question of "Can the Balanced Scorecard be developed and implemented as an effective organizational performance measurement system in star-class hotels in Sri Lanka?"
\end{abstract}

To address the objectives of the study, a mixed method research approach was adopted by utilizing multiple case studies. Five star-class hotels were selected as case studies, covering entire geographical area of the country. Data were gathered through documentation review; interviews with the top management; and a questionnaire administered among senior and middle level managers.

The study found that hotels were more concerned about financial and customer perspectives when measuring hotel performance and a lower degree of attention was given to internal business perspective, and innovation and learning perspective. Further, interviews raised some important concerns, which need to be addressed when implementing BSC in the hotel sector in Sri Lanka.

Key Words: Balanced Scorecard, Performance Measurement System, Star-class Hotels, Sri Lanka

\section{INTRODUCTION}

Travel and tourism sector is one of the rapidly growing industries in Sri Lanka playing a significant role in national economy. It contributed 9.5 billion US dollars to the gross domestic production (GDP) in 2016. Over the past two decades, contribution from travel and tourism industry to GDP grew substantially from 1.1 billion to 9.9 billion US dollars. During the recent decades, the tourism industry has become an effective source for monetary gains and economic growth (Karunarathne and Jayawardena, 2010). consequently, the hotel sector has become an important element in the national economy. Further it was evident that the industry has been identified by Central Bank of Sri Lanka as one of the key areas to achieve sustainable growth in Sri Lanka.

During the past few decades both professionals and academics have given an increasing attention to the importance of having strategic performance measurement systems, including both non-financial and financial measures, to an organization. One of the well-recognized approaches is the balanced scorecard introduced by Kaplan and Nortan (1992).
Based on the empirical evidence (Fonseka, 2001; Wickramasinghe et al, 2007; Gooneratne, 2013; Weerasooriya, 2013), it was observed that some Sri Lankan companies adopt the concept of balanced scorecard to measure their organizational performance. However, there is a lack of research, examining the use of balanced scorecard, in the hotel industry. As a rapidly growing industry, having a model to measure overall organizational performance is important to ensure sustainable development in hotel industry.

Therefore, the current study attempts to address whether a balanced scorecard can be developed and implemented as an effective organizational performance measurement system in star-class hotels in Sri Lanka.

\section{LITERATURE REVIEW}

Kaplan and Norton in 1992 introduced the concept of BSC as a comprehensive measurement of organizational performance. BSC presents a tool for translating an organisation's mission (embodied in its strategy) into more tangible measurable goals, actions and performance measures (Evans, 2005). The concept of BSC measures organizational performance in a broad range of perspectives rather limiting to traditional finance-based perspective. Indeed, the traditional use of profit-based performance measures by many organizations has been criticized on a variety of fundamental grounds-for instance their relative incompleteness and lack of accuracy and neutrality (Emmanuel et.al., 1990).

According to Kaplan and Norton (1993, 1996a, 1996b), a scorecard is appropriate for a business unit that has its own customers, distribution channels, production facilities, and financial performance measures. Brown and McDonnell (1995) studied the application of balanced scorecard in a UK hotel group to assess whether it can address the drawbacks of traditional methods. They developed a comprehensive balanced scorecard covering all aspects of performance and concluded that managers should have a very clear idea about the business unit for which the balanced scorecard is developed. This finding is consistent with the claim made by Kaplan and Norton (1993, 1996c) and Evans (2005).

In relation to Sri Lankan context, Fonseka (2001) studied the application of BSC framework to tea export firms of Sri Lanka. The researcher selected 14 tea export companies in Sri Lanka and conducted an exploratory study. The study found that the BSC should be in line with organizational culture of each organization.

Weerasooriya (2013) carried out a study on the application of BSC to measure performances of Sri Lankan universities. 
The researcher selected 39 department heads of management faculties of Sri Lankan universities. The study found that BSC framework can be successfully applied to non-profit organizations as well.

Wickramasinghe et al (2007) identified the reasons for rise and fall of BSC projects in Sri Lanka. The "rise" was due to a series of attempts made by CIMA (SL) for popularizing BSC practice among business leaders and local consultants, and the "fall" was due to professional rivalry between engineering managers and accounting personnel and the decline of interest on the part of the owner-manager. The study also emphasized that all relevant parties should be dedicated and take responsibility to ensure successful implementation of BSC.

Phillips and Louvieris (2005) examined performance measurement systems in small and medium sized hotels. They selected UK based best performing eleven hotels as the sample and they interviewed 38 personals covering consultants, owners and managers. They found priority factors that are slightly different from Kaplan and Norton's (1993) perspectives and stated that it is not accurate to design a BSC for small and medium size organizations, based on a BSC which is originally designed for larger organizations.

Wadongo et al (2010) found that, hospitality managers in Kenya are still focusing on financial and result-based measures of performance while ignoring non - financial and other determinant measures. Further, they claimed that demographic characteristics of managers such as age, education level, current position, functional area, and performance appraisal affect the choice of key performance indicators.

Evans (2005) study found that the majority of Northern England hotel managers are aware of BSC. Further he identified a few practical difficulties that can arise at the time of implementation such as failing to establish causal linkages between scorecard components and failing to get the support of employees for the management system. Therefore, it was noted that careful attention should be made at the time of BSC implementation to get the support from all the parties.

Borza and Bordean (2006) have explained BSC implementation in detail with reference to Romania's tourism sector. This study also emphasized the need for having a better communication among all parties for effective implementation of BSC, as stated by Evans (2005).

Kartalis et al, (2013) analyzed the theoretical and practical approach of strategic BSC and highlighted the advantages and disadvantages of the model.

Parkan (2005) identified that benchmarking is not a good tool for operational performance measurement since vision and objectives of an organization vary from organization to organization. But he highlighted that the BSC approach developed by Kaplan and Norton (1993) starts with vision and measures performance accordingly.

While scholars such as Vij (2012), Parkan (2005), and Golembski (2007) emphasized the importance of having financial measures, Nagy et al (2011) pointed out the importance of having non-financial measures for measuring performance in hotels.

Most of the past research related to BSC have been carried out by researchers, focusing on different industries in different countries. Thus, it is apparent that there is a lack of studies in relation to Sri Lankan hotel context.

\section{METHODOLOGY}

Due to the nature of the research question specified in this study, the researcher selected the case study approach as the most suitable approach since as it addresses the questions of "how" and "why" relating to a particular scenario. A case study is defined as "an empirical inquiry that investigates a contemporary phenomenon within its real-life context, especially when the boundaries between phenomenon and context are not clearly evident"' (Yin, 2003).

Five star-class hotels were selected for the study covering entire geographical area of Sri Lanka. Those five hotels included both five-star and four-star hotels. The sample hotels are referred as A, B, C, D, and E in this article to ensure the confidentiality of information as agreed with managers at the time of conducting interviews.

The research focused on currently used performance measurement methods and implementation of BSC with emphasis on emerging issues within star-class hotels in Sri Lanka. To achieve this objective, the researcher adopted a mixed approach. The data collection was done in two phases. The first phase included the distribution of a questionnaire to understand current organizational performance measurement systems used in star-class hotels in Sri Lanka. The questionnaires were distributed online among 62 four-star-class and 19 five-star-class hotels in Sri Lanka. The focused group was 81 managers from four and five-star-class hotels. The second phase involved interviews with star-class hotel managers to identify how to implement BSC in an effective way as a performance measurement tool. Five managers from each star-class hotel were interviewed and interviews lasted for one hour on average. In addition to those methods, the researcher observed various published documents.

\section{FINDINGS AND DISCUSSION}

The first objective of the study was to find out the currently used performance measures in star-class hotels in Sri Lanka. Respondents were requested to specify their frequency of usage of performance measures on a seven-point time scale. It included the scales, namely, "Daily"; "Weekly"; "Monthly"; "Quarterly"; "Annually"; "On ad-hoc basis" and "Never". To identify the currently used performance measures, frequency distribution analysis was performed. Further, questionnaire results were triangulated with the findings of interviews carried out with managers.

\section{A. Frequency of financial perspective related performance measures}

Based on the frequency distribution analysis, it seems majority of financial perspective related measures are monitored within a period of one month. Results revealed that $96 \%$ of hotels measure total operating revenue within a period of one month. All the hotels used for the study measure revenue per available room within a period of one month. Further $81 \%$ of hotels measure occupancy ratio on a daily basis. Hotel's occupancy vs. competitors' occupancy is measured by $92 \%$ of hotels within a period of one month. Further, actual revenue vs. budgeted revenue was measured by $92 \%$ of hotels within a one-month period. $88 \%$ of hotels measure budgeted cost vs. actual cost within one-month period. Therefore, it is evident that the measures come under financial 
perspective is highly considered by Sri Lankan star-class hotel managers as a performance measurement. This finding was confirmed through the interviews where mangers stated that they consider operating income and occupancy ratio as major concerns of financial perspective related performance measures. The finance manager of Hotel $\mathrm{C}$ commented:

"We give more attention on two measures on daily basis. Those are occupancy ratio and total net income. Hotels perform special function called night audit on daily basis. This night audit function starts at twelve mid-night. Night auditor checks all the transaction of the day and prepares a standardized report called night audit report. This is a one-page summarized report which includes all the important measures of the day. The report consists of total cash and credit sales under each segment, today's gross revenue and net revenue, month to-date and year to-date net revenue, today's occupancy ratio and month to-date occupancy ratio. Therefore, at a glance we can identify day's performance"

The above finding is consistent with the findings of Brown and McDonnell (1995) where they found that the most commonly used performance measure in US hotel industry is occupancy percentage.

\section{B. Frequency of Customer perspective related performance measures}

To analyse customer perspective related performance measures, the study used guest comment cards evaluation, review of web sites, mystery guests, market share of the hotel/group, number of complaints reported and returning guests as customer perspective measures. The frequency distribution analysis for a period of one month revealed that hotels are more concerned about returning guests (97\%), review of web sites $(90 \%)$ and guest complaints $(87 \%)$. Therefore, it seems that hotels recognize the importance of guest satisfaction over the other factors. It was observed that $20 \%$ of hotels identify market share either on ad-hoc basis or not at all. But with the increasing competition, it is essential to identify new markets to increase the occupancy level. The above findings were further confirmed by the hotel managers during the interviews. Resident Manager of hotel D commented:

"Customer satisfaction is our main concern. In long run, it will lead to attraction of new customers because of word of mouth. Therefore, continuous attention should be given to customer requirements"

Reservation Manager from hotel A also commented, emphasizing the importance of customer perspective in hotel industry.

"As we are working at service industry, both production and selling is occurred at the same place. For example, if a person is manufacturing soap at a factory, his working conditions do not affect customer satisfaction. Customers just purchase the product from supermarket. But in hotel industry, the way we process foods, the way we clean the room, how we behave highly influence customer satisfaction"

General Manager of hotel E commented:

"If customers are happy with our service, they will repeat in every year. We have some customers who visit our hotel continuously more than fifteen years. Therefore, this ensures the hotel income and need less effort on advertising"

These findings are consistent with the findings of Sainaghi et al. (2013) who stated that financial performance can be improved by generating strategies that enhance sales, customer satisfaction and customer loyalty.

Managers from hotel $\mathrm{C}$ and $\mathrm{D}$ also mentioned that every day they review customer comments mentioned in the web sites such as booking.com, trip adviser, Agoda.com etc. this finding is consistent with the findings of Nagy et al (2011) where they found that review of guest comments on web sites was an effective method of determining guest satisfaction.

\section{Frequency of Internal business perspective related performance measures}

Identification of service errors, staff salary cost, employee turnover and revenue by departments were used as internal business process perspective measures. Frequency analysis for a period of one month revealed that managers are more concerned on staff salary cost $(96 \%)$ and identification of service errors $(93 \%)$. These findings were further verified and confirmed through the interviews. Resident manager of hotel D commented:

"If our internal processors are good, we can satisfy customers and it will lead to better financial performances"

The importance of internal business perspective further explained by General Manager of hotel E:

"Certain activities we perform will appear to the guest, sometimes guest is waiting for the service. For instance, once a food order is received, we have a standard time to serve the guest. Within that time employees should perform it"

Research revealed the usage of different internal business perspective related performance measures in Sri Lankan hotels other than the measures used in this study which was based on the findings of Evans (2015). General Manager of hotel E commented:

"Reservation entering time, guest check-in time, room cleaning time, beverage and food serving time, bill settlement time are very important in operationally as hotels operates in service sector"

\section{Frequency of innovation and learning perspective related performance measures}

To measure innovation and learning perspective the study used measures such as new market identification, staff performance appraisal, setting staff targets, courses completed by staff members, improvements identification and process improvement meetings. The frequency distribution analysis for a period of one month revealed that hotels are more concerned about new market identification (44\%), setting staff targets (42\%) and process improvement meetings conducted (41\%). These findings were confirmed through the interviews made with hotel managers. Maintenance Manager of Hotel B commented:

"Innovation and learning is important to hotels, as we are competing with the global tourism market. Other competitive countries in the region do massive innovations compared to us" Maintenance manager of Hotel B commented:

"Under innovation, we try to identify new travel agents rather than fixing with limited travel agents. We visit to travel fairs to identify travel agents who can provide us customer segments which are more profitable"

These findings are consistent with the findings of Brown and McDonnell (1995) who stated that to be successful in the hotel industry, it must continually make improvements to their 
existing services and to their operations and processes, as well as develop and introduce new services.

\section{IMPLEMENTATION OF BALANCED SCORECARD}

The study identified important aspects in relation to the implementation of BSC for hotel industry in Sri Lanka. The BSC approach should start with vision and objectives of the organization and all the staff members should know the vision and objectives of the organization. It has been identified that even though the managerial level employees have sound knowledge about vision and objectives of the organization, the lower level employees are not much aware about them. Therefore, the vision should be cascaded to all levels of the hotel so that BSC can be successfully introduced and implemented in hotels. During the interview process, Reservation Manager of Hotel A commented:

"We cascade the vision at induction programmes. Further, we display it in common places such as board room, reception, stair case etc. But, majority of lower level employees' awareness about the vision is not adequate. They just believe it as a motto"

Further, BSC act as a performance driver and it helps managers to decide what should be done to achieve the objectives. Therefore, it seems that BSC will provide a clear path by defining critical success factors and related measures. Even though hotels use benchmarking as a performance measurement, it has been identified that benchmarking cannot be used effectively since objectives of different hotels differ. BSC provide a solution to this problem by identifying performance measures suitable for individual hotels. Reservation manager of Hotel A commented:

"According to industry standard the ratio of room to employees is 1:5. Our hotel consists 89 rooms and the standard labour requirement is 134. But we have around 200 employees. This will create a sense that we have excess staff and poor management. Actually, our hotel is an eco-friendly hotel located in a small island in Negombo. Guests need to travel via a ferry to the hotel, we need additional staff for logistic purposes; we have to focus more on security; we have bungalow type rooms and consume more time to clean a room. Therefore, I do not agree with the industry wide standards as it heavily depends on the individual company"

Information systems have been identified as a platform for BSC implementation and it was evident that hotels currently use sound information systems. However, it was revealed that there is lack of training given to the use of information systems of those hotels. Therefore, suitable information systems with appropriate training will lead to successful implementation of BSC in hotels. Further, BSC was identified as a way of satisfying all the stakeholder related measures of the hotel.

Based on the above facts it seems that there is a sound environment to implement BSC within the star-class hotels in Sri Lanka which may in turn help to develop industry-wide performance measurement systems within the hotel industry in Sri Lanka.

\section{CONCLUSION}

The research focused on currently used performance measurement methods and implementation of BSC within starclass hotels in Sri Lanka. The study revealed that hotels are more concerned about financial perspective and customer perspective when measuring hotel performances and low attention was given to internal business and innovation and learning perspective. Further, interviews raised some important concerns when applying BSC in the hotel sector in Sri Lanka. It includes lack of knowledge of lower level employees about strategic direction of the company, lack of training given to employees, and poor involvement of hotel industry regulator for the advancement of the industry as a whole. Therefore, by addressing those identified issues, the star-class hotels should be able to implement BSC successfully in their hotels. Properly implemented BSC will contribute to star-class hotels in Sri Lanka to measure hotel performance accurately and comprehensively.

The current study was mainly based on four- and five-star category hotels in Sri Lanka. The study can be further extended to other three categories as well. Further, in current context BSC concept is discussed together with sustainability. Therefore, it will be an interesting and advanced research area to examine how to incorporate Sustainable Balanced Scorecard (SBSC) in the hotel industry and identify related measures.

\section{REFERENCES}

Borza, A \& Bordea, O 2006, 'Performance measuring of tourism small medium size enterprises', International Conference on Business Excellence, Brasov, Romenia.

Brown, B \& McDonnell, B 1995, 'The balanced score-card: shortterm guest or long-term resident? ', International Journal of Contemporary Hospitality Management, vol. 7, no. 2/3, pp.7 - 11.

Central Bank of Sri Lanka - Annual Report 2013, [on line] Available from: http://www.cbsl.gov.lk/htm/english/02_prs/p_1.asp?yr=2013 (Accessed on $30^{\text {th }}$ December 2014)

Central Bank of Sri Lanka - Annual Report 2016, [on line] Available from:https://www.cbsl.gov.lk/en/publications/economic-andfinancial-reports/annual-reports/annual-report-2016 (Accessed on 06th December 2017)

Emmanuel, CR Otley, DT \& Merchant, K 1990, Accounting for Management Control, Chapman \& Hall, London.

Evans, N 2005, 'Assessing the balanced scorecard as a management tool for hotels', International Journal of Contemporary Hospitality Management, vol.17, iss. 5, pp. 376 - 390.

Fonseka AT 2001, 'Applying the balanced scorecard framework to tea export firms of Sri Lanka', Sri Lankan Journal of Management, vol. 6, nos. 3\&4, June/ December. 2001.

Golembski, G 2007, 'The impact of modern management methods on hotel operational performance', Tourism Review, vol.62, No. $2 / 2007$.

Gooneratne, TN 2013, 'Implementation of the balanced scorecard in a Sri Lankan firm A case study', Annual Research Symposium, University of Colombo, October 2013, pp.116.

Kaplan, RS \& Norton, DP 1992, 'The balanced scorecard - measures that drive performance', Harvard Business Review, January/February, pp. 1-79.

Kaplan, RS \& Norton, DP 1993, 'Putting the balanced scorecard to work', Harvard Business Review, September/October, pp.134-147. 
Kaplan, RS \& Norton, DP 1996a, 'Using the balanced scorecard as a strategic management system', Harvard Business Review, vol. 74, January/February, pp. 75-85.

Kaplan, RS \& Norton, DP 1996b, 'Linking the balanced scorecard to strategy', California Management Review, vol. 39, no.1, pp. 53-79.

Kaplan, RS \& Norton, DP 1996c,' The balanced scorecard', Harvard Business School Press Boston, MA.

Kaplan, RS \& Norton, DP 2001, 'The strategy-focused organization', Harvard Business School Press, Boston, MA.

Kartalis, N Velentas, J \& Broni, G 2013, 'Performance scorecard and performance measurement in a Greek industry', Procedia Economics and Finance, vol.5, pp.413-422.

Karunarathne, K \& Jayawardena, C 2010, 'Assessment of Customer Satisfaction in a Five Star Hotel: A case study', Tropical Agriculture Research, vol.21 (3), pp258-265.

Nagy, A Babaita, C \& Ispas, A 2011, 'Non- Financial measurement of hotel activity', Recent Research in Tourism and Economic Development.

Parkan, C 2005, 'Benchmarking operational performance: the case of two hotels', International Journal of Productivity and Performance Management, Vol.54, no.8, pp. $679-696$.

Phillips, P \& Louvieris, P 2005, 'Performance measurement systems in tourism, hospitality and leisure small medium - sized enterprises: A balance scorecard perspective', Journal of travel Research, pp.201-211.

Sainaghi, R Phillips, P \& Corti, V 2013, 'Measuring hotel performance: Using a balanced scorecard perspectives approach', International Journal of Hospitality Management, pp. 150-159.

Vij, M 2012, 'A survey of factors influencing cost structures in the Indian hotel sector', Worldwide Hospitality and Tourism Themes, vol. 4 no.5, pp. $449-462$.

Wadongo, B Odhuno, E Kambona, O \& Othuon, L 2010, 'Key performance indicators in the Kenyan hospitality industry: a managerial perspective benchmarking', An International Journal, vol. 17 , no.6, pp. $858-875$.

Weerasooriya, WMRB 2013, 'Performance evaluation using the balanced scorecard: the case of Sri Lankan universities', World Review of Business Research, vol.3, no.4, pp. 125-137.

Wickramasinghe, D Gooneratne, T \& Jayakody, JKSA 2007, 'Interest lost: the rise and fall of a balanced scorecard project in Sri Lanka', Envisioning a New Accountability (Advances in Public Interest Accounting), Emerald Group Publishing Limited, vol.13, pp. 237-271.

Yin, RK 2003, Case study research: Design and methods (3rd ed), Thousand Oaks: Sage, London. 